\title{
AVALIAÇÃO ANTIBACTERIANA DO EXTRATO DE MELALEUCA (Melaleuca alternifolia) FRENTE À CEPA DE Staphylococcus aureus ${ }^{1}$
}

\author{
Luana Tedesco ${ }^{2}$ \\ Aedra Carla Bufalo ${ }^{3}$ \\ Evellyn Claudia Wietzikoski ${ }^{4}$ \\ Patrícia Amaral Gurgel Velasquez ${ }^{5}$ \\ Gabriela Machado Ciesca ${ }^{6}$
}

TEDESCO, L.; BUFALO, A. C.; WIETZIKOSKI, E. C.; VELASQUEZ, P. A. G.; CIESCA, G. M. Avaliação antibacteriana do extrato de Melaleuca (Melaleuca alternifolia) frente à cepa de Staphylococcus aureus. Arq. Cienc. Saúde UNIPAR, Umuarama, v. 18, n. 2, p, 89-94, maio/ago. 2014.

\begin{abstract}
RESUMO: O uso de óleos essenciais para o tratamento de patologias de pele vem crescendo a cada dia, são facilmente comercializados para diferentes fins. Este trabalho visou a comparação e comprovação do efeito antimicrobiano do óleo essencial comercial de Melaleuca alternifolia e do óleo extraído direto da planta frente a cepa de Staphylococcus aureus (ATCC-25923). Para os testes foram escolhidos dois óleos comerciais tratados neste estudo como A e B e a extração do óleo da planta nas diferentes sazonalidades. A técnica utilizada para os testes foi a do poço por Pour Plate. A cultura bacteriana foi inoculada em placas de meio Ágar Mueller Hinton (MHA). A inoculação se deu com uma suspensão de colônias seguindo a escala de McFarland em salina estéril com concentração de 0,9 \%. A cada placa contendo o meio de cultura adicionou-se $1 \mathrm{ml}$ dessa suspensão do inoculo, em seguida foram realizados os poços com adição de $20 \mu 1$ de óleo, estes conservados em estufa a $37^{\circ} \mathrm{C}$ por 24 horas. Como controle positivo foi utilizado discos do antibiótico Eritromicina comercial. Todos os testes foram realizados e analisados em duplicata. Para a análise foram medidos o diâmetro dos halos de todas as amostras, os quais apresentaram uma discreta inibição. Conclui-se que o óleo essencial extraído em junho obteve maior inibição, sendo mais efetivo em Staphylococcus aureus do que os óleos comerciais A e B.
\end{abstract}

PALAVRAS-CHAVE: Staphylococcus aureus; Melaleuca alternifolia; Óleo essencial.

\section{ANTIBACTERIAL EVALUATION OF MELALEUCA (Melaleuca alternifolia) EXTRACT IN FACE OF Staphylococcus aureus STRAIN}

ABSTRACT: The use of essential oils for the treatment of skin diseases is growing. They are easily marketed for different purposes. This study sought to compare and prove the antimicrobial effect of the commercial essential oil of Melaleuca alternifolia and oil directly extracted from the plant with the strain of Staphylococcus aureus (ATCC 25923). For the tests, two commercial oils were chosen, treated in this study as A and B, and the oil extracted from the plant in the different seasonalities. The technique used for the tests was the Pour Plate well. The bacterial culture was inoculated onto plates with Mueller Hinton Agar (MHA). Inoculation took place with the suspension of colonies following the McFarland scale in $0.9 \%$ sterile saline solution. A total of $1 \mathrm{ml}$ of this inoculum suspension was added to each plate containing the culture medium, then the wells were used with the addition of $20 \mu \mathrm{l}$ of oil. These were stored at $37^{\circ} \mathrm{C}$ for 24 hours. Antibiotic erythromycin commercial discs were used as positive control. All tests were performed and analyzed in duplicate. For the analysis, the diameters of all samples were measured, which showed a slight inhibition. It can be concluded that the essential oil extracted in June presented higher inhibition, being more efficient against Staphylococcus aureus than commercial oils A and B.

KEYWORDS: Staphylococcus aureus; Melaleuca alternifolia; Essential oil.

\section{Introdução}

Os Staphylococcus são agentes patogênicos gram-positivos não esporulantes que infectam geralmente a pele e ferimentos. Seu nome é de origem grega staphylé que significa "cachos de uva" isso porque as células desses cocos crescem em um padrão semelhante a um cacho de uva. A maioria dos Staphylococcus apresentam diâmetros entre 0,5 a $1 \mu \mathrm{m}$ (MURRAY et al., 2006; MADIGAN et al., 2010).

Duas espécies apresentam importância para o homem Staphylococcus aureus e Staphylococcus epidermidis. Ambas são patogênicas, porém a Staphylococcus aureus encontra-se com mais frequência em doenças humanas (MA-
DIGAN et al., 2010).

Os Staphylococcus são responsáveis por provocar uma variedade de doenças incluindo acne, furúnculos, pústulas, foliculite, carbúnculos, endocardite, entre outras (MADIGAN et al., 2010).

A acne é uma doença crônica bastante comum, principalmente entre os adolescentes (COSTA; MOTTA; GOLDSCHMIDT, 2008). É considerada uma doença do folículo pilossebáceo (SAMPAIO, 2007). Caracterizada por comedões, pústulas, e lesões nodulocísticas, a qual evolui de acordo com intensidade das lesões (ABRAHAM et al., 2011). Essa patologia afeta tanto homens quanto em mulheres, seu surgimento é dado durante a puberdade, em que a

DOI: https://doi.org/10.25110/arqsaude.v18i2.2014.5172

${ }^{1}$ Artigo original do projeto de pesquisa do ano de dois mil e treze intitulado Avaliação Antibacteriana do Extrato de Melaleuca (Melaleuca alternifolia) Frente a Cepa de Staphylococcus aureus, desenvolvido na Universidade Paranaense/ Unidade Universitária de Francisco Beltrão.

${ }^{2}$ Professora Assistente do Curso Superior de Tecnologia em Estética e Cosmética da Universidade Paranaense/ Unidade Universitária de Francisco Beltrão e Coordenadora do projeto de pesquisa. Avenida Júlio Assis Cavalheiro, 2000, CEP 85601-270, fone/fax (46) 3520-2800. E-mail: luanatedesco@unipar.br ${ }^{3}$ Professora Adjunta da Universidade Estadual do Oeste do Paraná - UNIOESTE. E-mail:aedrab@gmail.com

${ }^{4}$ Instituto de Ciências Biológicas e da Saúde, Diretora Executiva de Gestão da Pesquisa e da Pós-Graduação. E-mail: evellyn@unipar.br

${ }^{5}$ Professora Adjunta do Curso de Farmácia da Universidade Paranaense/ Unidade Universitária de Francisco Beltrão e Coordenadora do projeto de pesquisa. Avenida Júlio Assis Cavalheiro, 2000, CEP 85601-270, fone/fax (46) 3520-2800. E-mail: patigurgel@unipar.br

${ }^{6}$ Acadêmica PIC do Curso Superior de Tecnologia em Estética e Cosmética da Universidade Paranaense/Unidade Universitária de Francisco Beltrão. E-mail: gabyciesca@hotmail.com 
taxa hormonal encontra-se aumentada (HABIF, 2005). Para Abraham et al. (2011) é mais frequente no sexo masculino, porém mais persistente no sexo feminino, podendo aparecer também na fase adulta.

O desenvolvimento da acne está relacionado com alguns fatores importantes como: aumento da secreção sebácea, hiperqueratinização folicular, colonização do ducto sebáceo por bactérias e por fim inflamação (ABRHAM et al.., 2011). Estes fatores patogênicos estão inter-relacionados, são, portanto, uma sequência de eventos (HASSUN, 2000). A pele humana abriga centenas de fungos e bactérias resistentes e transitórias (MADIGAN et al., 2010), perante a isso estudos recentes apontam que a presença de Staphylococcus aureus nos processos de acne vulgar tem maior prevalência do que a bactéria Propionibacterium acne (BAHMANI; MEHRABANI, 2008).

Existem diversos recursos sendo utilizados para o tratamento desta afecção, dentre eles encontram-se determinados óleos essenciais. A savana brasileira é muito rica em plantas medicinais, muito utilizadas na medicina natural e no tratamento de doenças bacterianas. Dessas plantas são feitos extratos e óleos essenciais. O uso desses extratos como recurso terapêutico é conhecido desde a antiguidade (SIANI et al., 2000; PEREIRA et al., 2004).

Os óleos essenciais são substâncias lipofílicas obtidas através de plantas. As plantas produzem estes óleos para a sua própria sobrevivência, defendem a planta contra microrganismo e impedem a atração de insetos. Quimicamente a grande maioria dos óleos essenciais é constituída de substâncias terpênicas e fenilpropanoides, acrescidos de moléculas menores, álcoois, ésteres, aldeídos, e cetonas da cadeia curta. São obtidos por meio das folhas, resina, caule, haste, casca, raízes, flores, semente e dos frutos (SIANI et al., 2000; SANTURIO et al., 2007; MALUF, 2008).

Vários estudos apontam algumas propriedades dos óleos essenciais, eles podem ser: antivirais, analgésica, cicatrizante, anti-inflamatória, antiseptica, antiespamódicas, relaxantes, expectorantes, larvicidas, vermífuga, bactericida entre outras indicações (NASCIMENTO, 2007).

Diversos são os óleos essenciais utilizados para o tratamento de diferentes patologias e em destaque o óleo de melaleuca que apresenta indicações para o tratamento da acne. A melaleuca (Melaleuca alternifolia) é uma pequena árvore ou arbusto de origem australiana, suas folhas são parecidas com agulhas e as flores são amarelas ou arroxeadas, mundialmente esta planta é também denominada de Tea Tree. O seu óleo é utilizado há muitos anos pelos aborígenes no tratamento de doenças (SIANI et al., 2000; HOARE, 2010). Em 1927, a melaleuca foi batizada como a "Árvore do chá" pela tripulação do Capitão Cook, que em diversas situações trocava os chás tradicionais por folhas escuras da planta (SELLAR, 2002).

O seu óleo é extraído das folhas e ramos pelo processo de destilação a vapor ou pela água, e seus principais componentes químicos são os terpenos, cineol, pineno, terpinenos, cimeno, sesquiterpenos e álcoois sesquiterpenos. Apresenta ação antisséptica, antimicótica, antibiótica, antiviral, expectorante, bactericida, bacteriostática, fungicida, germicida, imunoestimulante, analgésico e cicatrizante (MALUF, 2008; GOMES, 2009; HOARE, 2010). Na pele o seu uso desempenha um papel importante na redução do pro- cesso inflamatório de uma ferida infeccionada, furúnculos e acne (SELLAR, 2002).

Portanto, este artigo objetivou a comparação e comprovação do efeito antimicrobiano do óleo essencial comercial de Melaleuca alternifolia e do óleo extraído direto da planta frente a cepa de Staphylococcus aureus (ATCC25923).

\section{Materiais e Método}

\section{Obtenção dos óleos}

Para esta pesquisa foi escolhido trabalhar com dois óleos essenciais industrializados, tratados neste estudo como A e B e a extração direta da planta melaleuca nas sazonalidades, para comprovar e comparar sua ação antibacteriana.

A planta escolhida fica localizada na Rua Palmas $\mathrm{N}^{\circ}$ 2410, Bairro Nossa Senhora Aparecida na cidade de Francisco Beltrão - Paraná. Foram então coletadas as folhas da planta nas diferentes épocas sazonais, sendo a primeira colhida na data de trinta e um de outubro de dois mil e doze, a segunda no dia trinta e um de janeiro de dois mil e treze, a terceira no dia quatro de abril de dois mil e treze e a última e quarta no dia vinte e oito de junho de dois mil e treze. As folhas passaram por um processo de secagem no laboratório de química I da Universidade Paranaense/ Unidade Universitária de Francisco Beltrão por cinco dias em temperatura média de $32^{\circ} \mathrm{C}$, após a secagem foram devidamente armazenadas em sacos de papel até a data das extrações.

\section{Extração do óleo essencial}

A extração do óleo essencial foi realizada no laboratório de Fisiologia da Universidade Paranaense/Unidade Universitária de Francisco Beltrão e o método utilizado foi a hidrodestilação por meio do equipamento Clevenger a qual foi utilizado balões de 500, 1000 e $2000 \mathrm{ml}$. O período de realização das extrações foi de vinte e cinco de junho de dois mil e treze à cinco de julho de dois mil e treze.

Para a extração do dia trinta e um de outubro de dois mil e doze foram utilizados $390,58 \mathrm{~g}$ de folhas para $5950 \mathrm{ml}$ de água, do dia trinta e um de janeiro de dois mil e treze foram $480,47 \mathrm{~g}$ de folhas para $7100 \mathrm{ml}$ de água, do dia quatro de abril de dois mil e treze foram $510,20 \mathrm{~g}$ de folhas para $7500 \mathrm{ml}$ de água e para o dia vinte e oito de junho de dois mil e treze foram utilizados $450,37 \mathrm{~g}$ de folhas para $6300 \mathrm{ml}$ de água.

\section{Armazenamento do óleo}

O óleo essencial obtido durante a extração foi armazenado em tubos de ensaio envolto por papel alumínio e conservado em refrigerador. Os óleos essenciais A e B comerciais foram também armazenados em refrigeração. Eles só foram retirados da refrigeração para a realização dos testes antimicrobianos.

\section{Testes Antimicrobianos}

Para avaliar a atividade bactericida dos óleos essenciais sobre cepas padrões de Staphylococcus aureus (ATCC-25923), foi utilizada a técnica do poço por Pour Pla- 
te. Primeiramente a cultura foi inoculada em placas de meio Ágar Mueller Hinton (MHA). A inoculação se deu com uma suspensão de colônias, seguindo a escala de McFarland em salina estéril com concentração de $0,9 \%$. A cada placa contendo o meio de cultura adicionou-se $1 \mathrm{ml}$ dessa suspensão de inóculo, em seguida foram realizados os poços com adição de $20 \mu \mathrm{l}$ de óleo, estes conservados em estufa a $37^{\circ} \mathrm{C}$ por 24 horas. Para este foi também utilizado como controle positivo discos do antibiótico Eritromicina comercial.

\section{Processamento e Análise dos Dados}

Para avaliação dos resultados de inibição bacteriana foi realizada a medição dos halos utilizando o paquímetro da marca Kamasa ${ }^{\circledR}$ (Vernier Caliper $0-200 \mathrm{~mm}$ ), sendo este medido somente onde o halo encontrava-se com diâmetro perfeito.

Além da realização das medidas dos halos, as placas foram fotografadas com a câmera digital da marca Sony de 14.0 mega pixels sobre um pano azul marinho.

Os dados obtidos pela medição por paquímetro foram somados e divididos pelo numero de halos das placas, os quais totalizaram 6 halos por amostra, sendo 3 em cada uma das placas que passaram por duplicata.

\section{Resultados e Discussão}

\section{Análise de rendimento do óleo extraído}

Na tabela I são apresentados os resultados de rendimento dos óleos essenciais extraídos nas diferentes sazonalidades. De acordo com os dados é possível observar que o óleo essencial extraído das folhas coletadas no mês de Junho obteve um melhor rendimento, em comparação com os demais.

Tabela 1: Apresentação dos dados obtidos na analise de rendimento dos óleos essenciais extraídos.

\begin{tabular}{lcccc}
\hline Extração & Folhas & Água & Rendimento (g) & Rendimento \%) \\
\hline Outubro/2012 & $390,58 \mathrm{~g}$ & $5950 \mathrm{ml}$ & $1,13 \mathrm{~g}$ & $0,28 \%$ \\
Janeiro/2013 & $480,47 \mathrm{~g}$ & $7100 \mathrm{ml}$ & $1,25 \mathrm{~g}$ & $0,26 \%$ \\
Abril/2013 & $510,20 \mathrm{~g}$ & $7500 \mathrm{ml}$ & $1,90 \mathrm{~g}$ & $0,37 \%$ \\
\hline Junho/2013 & $450,37 \mathrm{~g}$ & $6300 \mathrm{ml}$ & $1,64 \mathrm{~g}$ & $0,36 \%$ \\
\hline
\end{tabular}

\section{Análise dos halos de inibição após testes antimicrobianos}

Após os testes antimicrobianos foram realizadas as medições dos halos de todas as placas. Os dados da análise dos óleos essenciais extraídos nas diferentes sazonalidades, os comerciais A e B e do antibiótico Eritromicina, são apresentados na Tabela 2 e Figura 1 e 2.
É possível observar que o óleo essencial extraído no mês de junho obteve resultado de inibição melhor em comparação com os outros óleos. Além deste, é possível observar também que o óleo extraído direto das folhas da planta, apresentou melhor resultado inibitório que os óleos comerciais $\mathrm{A}$ e B utilizados neste estudo. Estes resultados estão apresentados conforme Tabela 2 e Figura 1 e 2.

Tabela 2: Apresentação dos dados obtidos na análise dos halos de inibição.

\begin{tabular}{|c|c|c|c|c|c|c|c|}
\hline Placas & & & Hal & ição & & & Resultados \\
\hline Outubro/2012 & 0,6 & 0,4 & 0,5 & 0,6 & 0,4 & 0,5 & $0,5 \mathrm{~mm}$ \\
\hline Janeiro/2013 & 0,6 & 0,4 & 0,4 & 0,4 & 0,3 & 0,3 & $0,4 \mathrm{~mm}$ \\
\hline Abril/2013 & 0,5 & 0,4 & 0,5 & 0,3 & 0,4 & 0,3 & $0,4 \mathrm{~mm}$ \\
\hline Junho/2013 & 1,4 & 1,4 & 0,8 & 0,0 & 0,0 & 0,0 & $12 \mathrm{~mm}$ \\
\hline Comercial A & 0,5 & 0,5 & 0,3 & 0,4 & 0,4 & 0,3 & $0,4 \mathrm{~mm}$ \\
\hline Comercial B & 0,6 & 0,4 & 0,5 & 0,6 & 0,4 & 0,5 & $0,5 \mathrm{~mm}$ \\
\hline Antibiótico Eritromicina & 2,6 & 2,4 & 2,5 & 1,9 & 1,5 & 1,7 & $21 \mathrm{~mm}$ \\
\hline
\end{tabular}




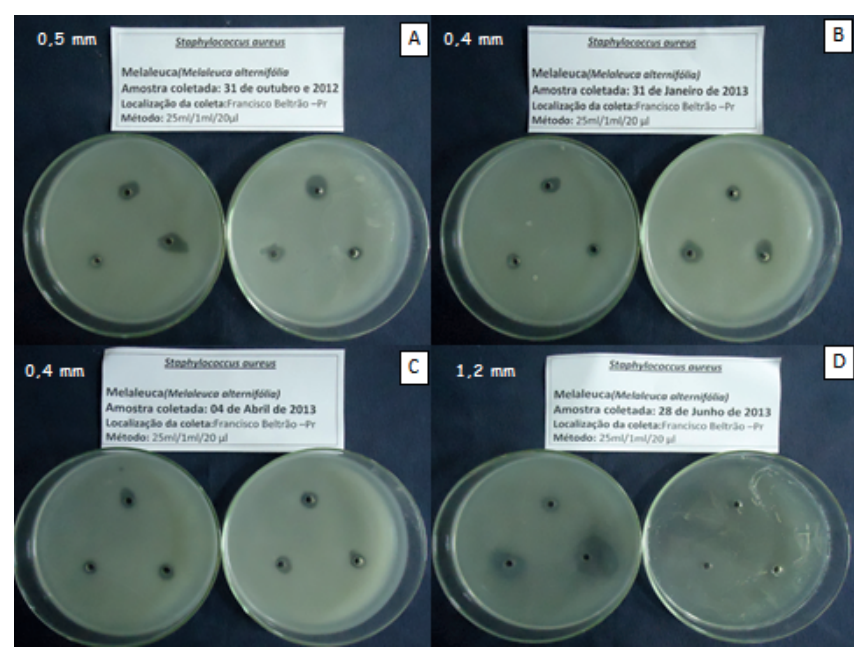

Figura 1: Placas (A) teste antimicrobiano em Staphylococcus aureus (ATCC-25923) utilizando óleo essencial extraído das folhas coletadas no dia trinta e um de outubro de dois mil e doze $(25 \mathrm{ml}$ de meio MHA $/ 1 \mathrm{ml}$ de suspensão de inóculo bacteriano $/ 20 \mu 1$ de óleo). Placa (B) teste antimicrobiano em Staphylococcus aureus (ATCC25923) utilizando óleo essencial extraído das folhas coletadas no dia trinta e um de janeiro de dois mil e treze $(25 \mathrm{ml}$ de meio MHA $/ 1 \mathrm{ml}$ de suspensão de inóculo bacteriano $/ 20 \mu 1$ de óleo). Placas (C) teste antimicrobiano em Staphylococcus aureus (ATCC-25923) utilizando óleo essencial extraído das folhas coletadas no dia quatro de abril de dois mil e treze ( $25 \mathrm{ml}$ de meio MHA $/ 1 \mathrm{ml}$ de suspensão de inóculo bacteriano $/ 20 \mu 1$ de óleo). Placas (D) teste antimicrobiano em Staphylococcus aureus (ATCC-25923) utilizando óleo essencial extraído das folhas coletadas no dia vinte e oito de junho de dois mil e treze $(25 \mathrm{ml}$ de meio MHA $/ 1 \mathrm{ml}$ de suspensão de inóculo bacteriano $/ 20 \mu 1$ de óleo).

Simões et al. (2002), realizaram testes in vitro e in vivo do óleo de melaleuca a qual foi importada da Austrália, frente a estafilococos sensíveis a penicilina (Staphylococcus aures ATCC25923, ST79/741, NCTC9789, DK3177, DK3177, FAR10, RN9). Para os testes in vivo foram utilizados 18 amostras (ratos) macho, adultos jovem com peso entre 150 e $200 \mathrm{~g}$. Os objetivos desses pesquisadores foram avaliar a atividade antimicrobiana, sendo que concluíram que o óleo de melaleuca apresenta propriedades antimicrobiana in vitro sobre cepas de estafilococos resistentes in vitro/vivo sobre estafilococos sensíveis a penicilina.

Packer (2007) em sua pesquisa comparou a ação antimicrobiana e antifúngica dos óleos de copaíba, alecrim, melaleuca, alho, andiroba, própolis, extra da folha de oliva e o farnesol, frente a cepa das bactérias Staphylococcus aures (ATCC 6538), Escherichia coli (ATCC 8739), Pseudomonas aeruginosa (ATCC 9027) e Candida albicans (ATCC 10231), em placas de cultura, em que comprovou que o óleo de melaleuca e alecrim apresentam maior atividade bactericida e fungicida.

Enshaieh et al. (2007) realizaram um estudo para avaliar a eficácia de um gel a 5\% de óleo de melaleuca, que refere-se como óleo da arvore do chá, a pesquisa foi realizada com 60 voluntários que apresentaram acne vulgar de grau leve a moderado (comedões, pápulas, pústulas) , com idade entre 15 a 25 anos. Os voluntários foram divididos em dois grupos A e B. Sendo o grupo A tratado com o gel de melaleuca a 5\% e o grupo B com placebo. Os voluntários foram orientados a aplicar o produto duas vezes ao dia sobre as áreas afetadas por 20 minutos e depois removidas com

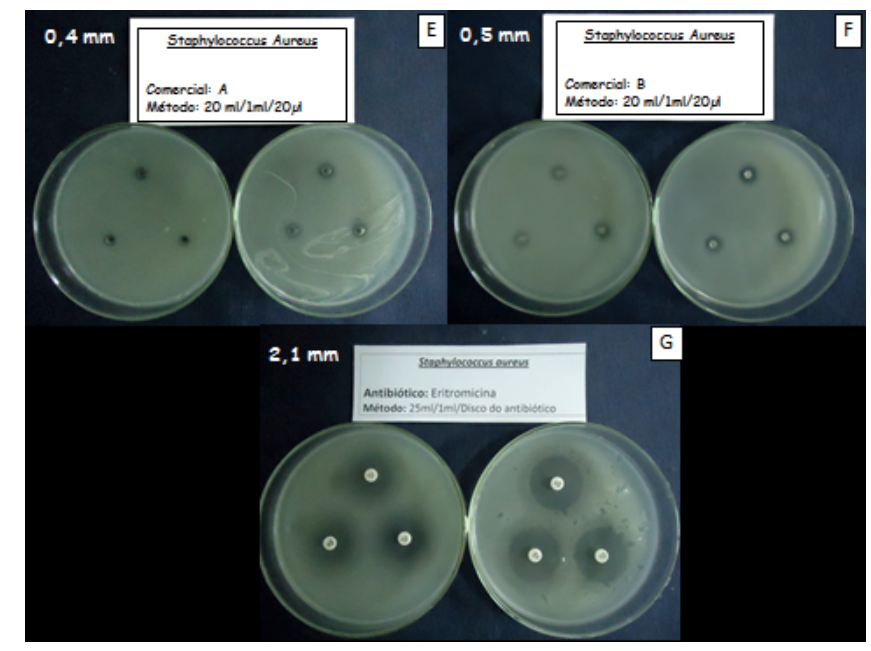

Figura 2: Placas (E) teste antimicrobiano em Staphylococcus aureus (ATCC-25923) utilizando óleo essencial comercial A (25 ml de meio MHA $/ 1 \mathrm{ml}$ de suspensão de inóculo bacteriano $/ 20 \mu 1$ de óleo). Placa (F) teste antimicrobiano em Staphylococcus aureus (ATCC25923) utilizando óleo essencial comercial B ( $25 \mathrm{ml}$ de meio MHA $/ 1 \mathrm{ml}$ de suspensão de inóculo bacteriano $/ 20 \mu 1$ de óleo). Placas $(\mathrm{G})$ teste antimicrobiano em Staphylococcus aureus (ATCC-25923) utilizando discos do antibiótico Eritromicina como controle positivo ( $25 \mathrm{ml}$ de meio MHA $/ 1 \mathrm{ml}$ de suspensão de inóculo bacteriano/discos do antibiótico).

água, num período total de 45 dias. A cada 15 dias eram então reavaliados para descartar possíveis reações e avaliar os resultados. Os método de avaliação usadas foram contagem das lesões e o índice de gravidade das acnes. Ao final concluíram que a utilização do óleo desta planta a 5\% topicamente apresenta resultados satisfatórios neste grau de acne.

Outra pesquisa importante tal como a de Faria et al. (2012) comprovaram a ação bactericida do óleo de melaleuca sobre Porphyromonas gingivalis, um bacilo gram negativo anaeróbico que promove lesões inflamatórias, resultando em destruição do ligamento periodontal e do osso alveolar. Os testes foram realizados em condições anaeróbicas sobre placas de cultura. Para as culturas em tubos foi utilizado o meio TSB (Tryptic Soy Broth) e para o cultivo em placas TSA (Tryptic Soy Agar) com 7\% de sangue de carneiro desfibrinado ambos acrescido de extrato de levedura à $2 \%$, hemina $5 \mu \mathrm{g} / \mathrm{ml}$ e menadiona $1 \mu \mathrm{g} / \mathrm{ml}$. Para o teste controle foi então utilizado solução de digluconato de clorexidina nas concentrações: $100 \mu \mathrm{g} / \mathrm{ml}, 25 \mu \mathrm{g} / \mathrm{ml}, 6,25 \mu \mathrm{g} / \mathrm{ml}, 1,5 \mu \mathrm{g} / \mathrm{ml}$ e 0,38 $\mu \mathrm{g} / \mathrm{ml}$ e as concentrações de melaleuca utilizada nesta pesquisa foram: $0,5 \%, 0,125 \%, 0,032 \%, 0,007 \%$ e $0,002 \%$. Faria et al. (2012) comprovaram em seu estudo que tanto o óleo de melaleuca quanto a solução de digluconato de clorexidina promoveram inibição do crescimento e morte da bactéria estudada com a concentração mínima.

Novacosk e Torres (2006) realizaram uma pesquisa em busca de uma mistura de óleos essencial para atuar como conservante natural de produtos cosméticos de ação bactericida, e para tal foram utilizados o óleo essencial de lavanda (Lavandula officinales), melaleuca (Melaleuca alternifólia), 
cedro (Juniperus virginiana), tomilho (Thymus vulgaris) e cravo (Eugenia caryophyllata). Os microorganismo utilizados neste estudo foram: Escherichia coli, Staphylococcus aures, Pseudomonas aeruginosa, Candida albicans e Proteus vulgaris. Os testes realizados foram para verificação da concentração inibitória mínima dos óleos isolados e em mistura frente a estes microrganismos, os óleos foram testados individualmente e em mistura numa porção de $20 \%$ e mantidos em frasco âmbar à temperatura ambiente. Nesta pesquisa Novacosk e Torres (2006), comprovam que os óleos essenciais isolados apresentaram atividade antimicrobiana exceto o óleo essencial de cedro e que a utilização da mistura dos óleos apresentam resultados satisfatórios na inibição bacteriana. A concentração de $0,5 \%$ dos óleos foi suficiente para inibir a ação dos microrganismos em estudo.

Em se falando de formulação cosmecêutica para o tratamento de acne, Diniz et al. (2007) avaliaram a estabilidade físico-químico de preparações tópicas do óleo de melaleuca para o tratamento da acne no qual realizaram 16 diferentes formulações usando o gel como veiculo. Para essa pesquisa foi então utilizado Natrosol $\AA$, Methocel $\AA$, Pemulen $\AA$, TR1 ${ }^{\circledR}$, Aristoflex $\AA$, AVC $\AA$, Salcare $\AA$, Plurigel ${ }^{\circledR}$, Amigel ${ }^{\circledR}$, Carbopol $^{\circledR}$, e associação de Natrosol ${ }^{\circledR}$ e Ami-

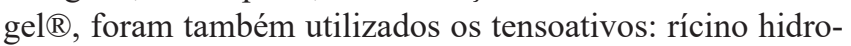
genado, etoxilado 20 O.E. (Cremophor $\AA$ ) e polissorbato 80 (Tween ${ }^{\circledR 80}$ ). Para cada polímero (gel) Diniz et al. (2007), manipularam duas formulação uma com Tween ${ }^{\circledR} 80$ e outra com Cremophor ${ }^{\circledR}$, o óleo de melaleuca foi acrescentado numa porcentagem de $5 \%$ e com $\mathrm{pH}$ de 5,5 e um antioxidante para prevenir a oxidação do óleo Butilhidroxitolueno. Para os testes de estabilidade, as formulações foram submetidas ao armazenamento em diferentes temperaturas: estufa (40 \pm $\left.2^{\circ} \mathrm{C}\right)$, geladeira $\left(5 \pm 2^{\circ} \mathrm{C}\right)$ e temperatura ambiente $\left(25 \pm 3^{\circ} \mathrm{C}\right)$. Além dos testes de estabilidade foram também analisados o tempo de exposição de cada formulação: tempo zero (24 horas após a fabricação), 7, 15, 30, 60 e 90 dias após. Após todos os levantamento gráficos Diniz et al. (2007) puderam concluir que as formulação desenvolvidas com Pemulen $\AA$, Aristoflex ${ }^{\circledR}$ AVC, Salcare ${ }^{\circledR}$ e Plurigel ${ }^{\circledR}$ TR1, mantiveram todos os parâmetros da formulação (cor, transparência, odor e sinérese) além da estabilidade em todas as temperaturas as quais foram submetidas, pelo período de 90 dias tempo máximo estipulados pelos pesquisadores.

Raman; Weir e Bloomfield (1995) tiveram como objetivo avaliar a ação antimicrobiana de duas amostras comerciais do óleo de melaleuca e seu componentes frente as bactérias Staphylococcus aureus, Staphylococcus epidermidis e Propionibacterium acnes. Nos seus estudos observa-se como resultado a inativação dessas bactérias, confirmando o uso da melaleuca no tratamento da acne.

Portanto, os resultados obtidos nesta pesquisa demonstram que o óleo essencial de melaleuca alternifolia apresenta importante efeito bactericida em Staphylococcus aureus.

\section{Conclusão}

Pode-se concluir com esta pesquisa que o óleo essencial extraído no mês de junho obteve resultado de inibição melhor em comparação com os outros óleos, concluindo ainda que este foi mais eficiente em Staphylococcus aureus que os óleos comerciais A e B utilizados na pesquisa.

É possível concluir ainda que a cada dia os extratos e óleos essenciais de plantas medicinais vêm ganhando destaque no tratamento de algumas patologias de pele, em especial o óleo essencial de melaleuca.

Portanto, fica manifesto o desafio para que novas pesquisas sejam realizadas, a fim de explorar ainda mais os benefícios e mecanismos de ação do óleo essencial de melaleuca alternifolia.

\section{Referências}

ABRAHAM, S. L. et al. Acne e doenças afins. In: AZULAY \& AZULAY. Dermatologia. 5. Ed. Rio de Janeiro: Guanabara Koogan, 2011. p. 506.

BAHMANI, H. P.; MEHRABANI. Bacterial resistance to antibiotics in acne vulgaris: na in vitro study. Indian Journal Of Dermatology. 53 (3): 122-124. 2008. Disponível em: http://www.ncbi.nlm.nih.gov/pmc/articles/ PMC2763741/?tool=pubmed. Acesso:27 de agosto de 2012.

COSTA, A.; ALCHORNE, M. M. A.; GOLDSCHMIDT, M. C. B. Fatores etiopatogênicos da acne vulgar. Anais Brasileiro de Dermatologia, v. 83, n. 5, 2008. Disponível em: http://www.scielo.br/scielo.php?script=sci_arttext\&pid =S0365-05962008000500010. Acesso em: 28 de janeiro de 2012 Às $15 \mathrm{~h} 00$.

DINIZ, et al. Desenvolvimento e avaliação da estabilidade físico- química de preparações tópicas contendo óleo de melaleuca para o tratamento da acne. Revista de Iniciação Científica Newton Paiva. Ed. 2006/2007. p.13 a 30. Belo Horizonte. 2007.

ENSHAIEH, et al. The efficacy of 5\% topical tea tree oil gel in mild to moderate acne vulgaris: A randomized, double-blind placebo-controlled study. Indian Journal of dermatology, venereology and leprology, v. 73, n. 1 pag. 22-24. 2007. Disponível em: http://ijdvl.com/article. asp? issn $=0378-6323$; year $=2007$; volume $=73$; issue $=1$; spage $=$ 22 ; epage $=25 ;$ aulst $=$ Enshaieh . Acesso em 26 de Outubro de 2012 às $16 \mathrm{~h} 10$.

FARIA, et al. Atividade do óleo de melaleuca alternifólia sobre o crescimento e expressão gênica de Porphyromonas gingivalis. Revista da Sociedade Brasileira de Periodontologia. v.22, issue 01, pag. 80-86, 2012. Disponível em: http://www. revistasobrape.com.br/arquivos/2012/marco/REVPERIOMAR\%C3\%87O-2012\%20-\%20PAG\%2080\%20A\%2086. pdf. Acesso em: 26 de Outubro de 2012 às $20 \mathrm{~h} 00$.

GOMES, R. K. Princípios ativos. In: Cosmetologia: descomplicando os princípios Ativos. 3 Ed. São Paulo: Livraria Médica Paulista, 2009. p. 177-371.

HABIF, T. P. Acne, Rosácea e doenças correlatas. In: Dermatologia clínica. 4 Ed. Porto Alegre - RS: Artemed, 2005. p. 176. 
HASSUN, M. K. Acne: etiopatogenia. Anais Brasileiro de Dermatologia, v. 75 n. 1, 2000. Disponível em: http:// scholar.googleusercontent.com/scholar?q=cache:1hdci9er OLEJ:scholar.google.com/+ropionibacterium+acnes\&hl= pt-BR\&lr=lang_pt\&as_sdt=0. Acesso em: 23 de janeiro de 2012.

HOARE, J. Guia completo de aromoterapia: um curso estruturado para alcançar a excelência profissional. São Paulo: Pensamento, 2010.

MADIGAN, T. M. et al. Interações dos micro-organismos com o homem. In: Microbiologia de Brock. $12^{\circ}$ Ed. Porto Alegre: Artemed. 2010. p. 811- 814.

MALUF, S. Principais óleos essenciais. In: Aromoterapia. $1^{\circ}$ Ed. São Paulo: Editora do Autor. 2008. p. $34-66$.

MURRAY, R. P.; ROSENTHAL, S. K.; PFALLER, A. M. Bactérias gran positiva anaeróbica, não esporuladas. In: Microbiologia Médica. $5^{\circ} \mathrm{Ed}$. Rio de Janeiro: Elsevier, 2006. p.407-412.

NASCIMENTO, F. C. P. et al . Atividade antimicrobiana dos óleos essenciais: uma abordagem multifatorial dos métodos. Revista Brasileira de Farmacologia, v.17, n. 1, 2007. Disponível em: http://www.scielo.br/pdf/rbfar/v17n1/ a20v17n1.pdf. Acesso em: 30 de janeiro de 2012.

NOVACOSK, R.; TORRES, R. S. L. A. Atividade Antimicrobiana sinérgica entre óleos essenciais de lavanda (Lavandula officinalis), Melalauca (Melaleuca alternifólia), Cedro (Juniperus virginiana), Tomilho (Thymus vulgaris) e Cravo (Eugenia caryophyllata). Revista Analytica. N $N^{o} 21$. Fev/Mar. p. 36-39. 2006.

PACKER, J. F. Método para avaliação e pesquisa da atividade antimicrobiana de produtos de origem natural.

Revista Brasileira de Farmacologia, 17(1): 102-107, Jan./ Mar. 2007. Disponível em: http://www.scielo.br/scielo. php?script=sci_arttext\&pid=S0102-695X2007000100019. Acesso: em 26 de Outubro de 2012 às 10h00.

PEREIRA, S. R. et al. Atividade antibacteriana de óleos essenciais em cepas isoladas de infecções urinária. Revista Saúde Publica, v. 38, n. 2, 2004. Disponível em: http:// www.scielo.br/pdf/rsp/v38n2/19796.pdf. Acesso em 28 de janeiro de 2012.

RAMAN, A.; WEIR, U.; BLOOMFIELD, S. F. Antimicrobial effects of tea-tree oil and its major components on Staphylococcus aureus, Staph. epidermidis and Propionibacterium acnes. Letters in Applied Microbiology, 1995, 21, 242-245

SAMPAIO, S. A. P. Foliculoses. In: . Dermatologia.

3. ed. São Paulo: Artes Médicas, 2007. p. 383.

SANTURIO, M. J. et al. Atividade antimicrobiana dos óleos essenciais de orégano, tomilho e canela frente a sorovares de Salmonela enterica de origem avícola. Revista Ciência Rural, v. 37, n. 3, 2007. Disponível em: http://www.scielo.br/scielo.php?script=sci_arttext\&pid $=$ S0103-84782007000300031. Acesso em: 29 de janeiro de 2012.

SELLAR, W. Os óleos essenciais. In: Óleos que curam: o poder da aromoterapia. $1 \mathrm{Ed}$. Rio de Janeiro: Record: Nova Era, 2002. p. 13- 250.

SIANI, C. A. et al. óleos essenciais. Revista biotecnologia ciência e desenvolvimento, Ano 3, n. 16, 2000. Disponível em: http:/www.biotecnologia.com.br/revista/bio16/16_ oleos.pdf. Acesso em: 29 de janeiro de 2012.

SIMÕES, P. R. et al. Efeito do óleo de melaleuca alternifolia sobre a infecção estafilocócica. Revista Lect. Bragança Paulista, v. 20, n2, p. 143-152, jul./dez. 2002. Disponível em: http://www.dbsaude.com.br/artigos/ arquivos/Estudo_melaleuca.pdf. Acesso: 24 de Outubro de 2012 às $11 \mathrm{~h} 15$. 